\title{
Age is not how old you are but how old you feel
}

\author{
Michele Di Mauro, MD, PhD, ${ }^{a}$ Massimiliano Foschi, MD, ${ }^{b}$ Fabrizio Tancredi, MD, ${ }^{b}$ and \\ Antonio M. Calafiore, MD
}

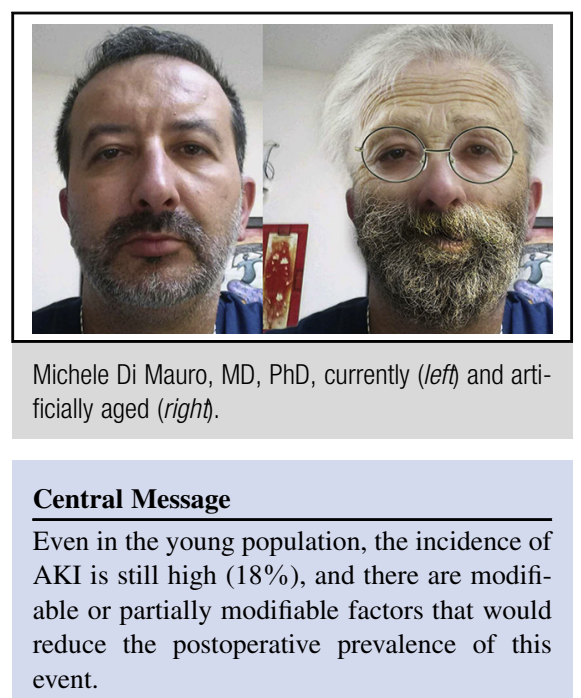

See Article page 256
If we paraphrase the novelist Gabriel Garcia Marquez's phrase, from which we took the title of this editorial commentary, we can state that age is not a matter of years, but how old we are, biologically speaking. This is the important message of the article in this issue of the Journal by Saydy and colleagues. ${ }^{1}$

Age has been always considered a risk factor for mortality in main predictive scores, such as EuroSCORE II and the Society of Thoracic Surgeons score. ${ }^{2,3}$ In the latter, age was also a risk factor for postoperative acute kidney injury (AKI), and this finding is confirmed by Saydy and colleagues, ${ }^{1}$ because older patients showed roughly double the rate of AKI seen in the younger group ( $34 \%$ vs $18 \%$ ). If the message of Saydy and colleagues ${ }^{1}$ were just this, this study probably would have added nothing new to what we already knew and would not even deserve to be published. The strong message of this study is to show that the incidence of AKI is still high even in the young population $(18 \%)$. There are modifiable or partially modifiable factors that would allow us to reduce the postoperative prevalence of this event; which strongly effects the outcomes of patients. In fact, the mortality of patients with AKI in the group of young people is $8 \%$, quite similar to that of the AKI group in elderly patients $(11 \%)$. Even if we consider those patients who needed renal replacement therapy, the young patients only show a slightly higher incidence $(15 \%$ vs $13 \%)$. This proves that being young or old does not matter; once an AKI has occurred, the likelihoods of undergoing renal replacement therapy or dying remain the same.

As we said, there are more or less modifiable risk factors that are similar in the 2 groups, such as hemoglobin, the use of diuretics, a long cardiopulmonary bypass time, and the use of intra-aortic balloon pulsation, which should be considered for young patients just as for old ones. In particular, anemia is often associated with chronic kidney disease, ${ }^{4}$ and in this subgroup of patients, the preoperative value of hemoglobin is a risk factor for postoperative
AKI, just as it is in the general population undergoing cardiac surgery. ${ }^{5}$ On can obviously disregard age factor in some cases, as in case of a young patient with diabetes, who may have nephropathy develop early and chronic renal disease, often leading to low values of hemoglobin as a clinical marker. In fact, in a young population, Saydy and colleagues $^{1}$ found that diabetes was a risk factor for postoperative AKI. What to do in these cases? Preoperative red blood cell transfusions or other treatments? Perioperative red blood cell transfusions along with preoperative anemia increase the risk of postoperative AKI.

The Kidney Disease Improving Global Outcomes and European guidelines state that erythropoietin-stimulating agents should not be used to maintain hemoglobin concentrations above $11.5 \mathrm{~g} / \mathrm{dL} .{ }^{6}$ Conversely, Cladellas and colleagues ${ }^{7}$ showed that combined therapy with intravenous erythropoietin and iron administered before valvular cardiac surgery in patients with anemia was associated with a significant improvement in postoperative outcomes and a significant decrease in need for red blood cell transfusions. Which is the target hemoglobin value to treat preoperatively? Shavit and coworkers ${ }^{8}$ found that preoperative hemoglobin values lower than $12 \mathrm{~g} / \mathrm{dL}$ (odds ratio, $2.7 ; 95 \%$ confidence interval, $1.1-7.9 ; P=.04$ ) and lower than $11 \mathrm{~g} / \mathrm{dL}$ (odds ratio, 2.6; 95\% confidence interval, 1.1-6.5; $P=.03$ ) were independent risk factors for RIFLE (Risk, Injury, Failure, Loss of kidney function, and End-stage kidney disease) stage failure and risk of 
postoperative AKI, respectively. Another interesting key point raised is the use of diuretics, which is becoming more and more often overemphasized in patients with heart failure or simply with left ventricular dysfunction, often regardless of the presence of water retention. It is understandable that excessive use of diuretics tends to stress the nephrons, so that they show some degree of dysfunction in the postoperative period, regardless the age of patients. The detrimental effect of cardiopulmonary bypass, caused by relative hypoperfusion and systemic inflammatory response, is already known; however, the study of Saydy and colleagues ${ }^{1}$ adds a new insight: we cannot afford long cardiopulmonary bypass times even in young people!

Obese patients constitute another interesting group of which we should be more aware, because in almost all cases, they have a metabolic syndrome with the simultaneous presence of several cardiovascular risk factors and associated polyvasculopathy. This study finally defeats what is called the "paradox" of obesity that, unconsciously, makes a warning message pass us by.

Finally, let's give a glance at intraoperative factors. Here, there is an important difference between the age groups. In fact, isolated coronary artery bypass grafting results in a greater incidence of postoperative AKI in young people but not in the elderly population. We agree with the possible explanation by Saydy and colleagues ${ }^{1}$ because undergoing coronary artery bypass grafting at a young age is certainly a sign of advanced atherosclerosis.
Before concluding, we must admit that we do not agree that cigarette smoking can be a risk factor in the elderly and not in young people. This result probably depends on using a categoric variable: smoking or not smoking. We believe that in addition to the duration of exposure to smoke, the number of smoked cigarettes per day can be decisive. We end by congratulating Saydy and colleagues for their extraordinary work.

People are never too young to be old!

\section{References}

1. Saydy N, Mazine A, Stevens LM, Jeamart H, Demers P, Pagé P, et al. Differences and similarities in risk factors for postoperative acute kidney injury between younger and older adults undergoing cardiac surgery. J Thorac Cardiovasc Surg. 2018;155:256-65.

2. Society of Thoracic Surgeons. Online STS adult cardiac surgery risk calculator Available at: http://riskcalc.sts.org/stswebriskcalc/\#/calculate. Accessed October 3, 2017.

3. Roques F, Michel P, Goldstone AR, Nashef SA. The logistic EuroSCORE. Eur Heart J. 2003;24:882-3

4. Singh AK, Szczech L, Tang KL, Barnhart H, Sapp S, Wolfson M, et al; CHOIR Investigators. Correction of anemia with epoetin alfa in chronic kidney disease. N Engl J Med. 2006;355:2085-98.

5. Karkouti K, Wijeysundera DN, Beattie WS, Reducing Bleeding in Cardiac Surgery $(\mathrm{RBC})$ Investigators. Risk associated with preoperative anemia in cardiac surgery: a multicenter cohort study. Circulation. 2008;117:478-84.

6. Kidney Disease Improving Global Outcomes. KDIGO clinical practice guideline for anemia in chronic kidney disease. Kidney Int Suppl. 2012;2:279-335.

7. Cladellas M, Farré N, Comín-Colet J, Gómez M, Meroño O, Bosch MA, et al. Effects of preoperative intravenous erythropoietin plus iron on outcome in anemic patients after cardiac valve replacement. Am J Cardiol. 2012;110:1021-6.

8. Shavit L, Hitti S, Silberman S, Tauber R, Merin O, Lifschitz M, et al. Preoperative hemoglobin and outcomes in patients with CKD undergoing cardiac surgery. Clin J Am Soc Nephrol. 2014;9:1536-44. 